\title{
Sorbitol and myo-inositol levels and morphology of sural nerve in relation to peripheral nerve function and clinical neuropathy in men with diabetic, impaired, and normal glucose tolerance
}

\author{
G. Sundkvist*, L. -B. Dahlint, H. Nilsson*, K. -F. Eriksson‡, F. Lindgärdeł, I. Rosén§, \\ S. A. Lattimerף, A. A. F. Simaף\#, K. Sullivanף and D. A. Greeneף\#
}

Departments of *Endocrinology, ¥Hand Surgery, $\neq$ ₹ascular and Renal diseases, and §Neurophysiology, University of Lund, Malmö University Hospital, Malmö, Sweden

Departments of $\boldsymbol{\eta}$ Internal Medicine and \#Pathology, University of Michigan, Ann Arbor, $\mathrm{MI}$, USA

Received 21 May 1999; revised 7 December 1999; accepted 9 January 2000

\begin{abstract}
Aims Sorbitol and myo-inositol levels and morphology of sural nerve were compared with nerve function and clinical neuropathy in men with diabetic, impaired (IGT), and normal glucose tolerance.

Methods After neurography of sural nerve and determinations of sensory thresholds for vibration, warm and cold on the foot, whole nerve sural nerve biopsy was performed in 10 men with Type 1 diabetes mellitus, 10 with IGT, and 10 with normal glucose tolerance. Polyol levels were assessed by gasliquid chromatography/mass spectrometry.

Results Sural nerve amplitudes were significantly lower and sorbitol levels significantly higher in diabetic patients (median (interquartile range)) (3.7 (3.5) $\mu \mathrm{V}$ and $643(412) \mathrm{pmol} / \mathrm{mg}$ protein, respectively) both compared with IGT $(11.3(10.6) \mu \mathrm{V} ; P=0.04$ and $286(83) \mathrm{pmol} / \mathrm{mg}$ protein; $P=0.0032$, respectively) and normally glucose tolerant $(10.0(11.6) ; P=0.0142$ and 296 (250) $\mathrm{pmol} / \mathrm{mg}$ protein; $P=0.0191$, respectively) subjects. There were no differences in nerve morphology between the three groups. Nerve myo-inositol levels correlated, however, positively with cluster density $\left(r_{\mathrm{s}}=0.56\right.$; $P=0.0054)$. In diabetic and IGT subjects, sural nerve amplitudes $(2.6(3.8)$ vs. $12.1(10.6) \mu \mathrm{V} ; P=0.0246)$ and myelinated nerve fibre density (MNFD; 4076 (1091) vs. 5219 (668) nerve fibres $/ \mathrm{mm}^{2} ; P=0.0021$ ) were significantly lower in nine subjects with clinical neuropathy than in 10 without.
\end{abstract}

Conclusions Nerve degeneration (i.e. MNFD) correlated with clinical neuropathy but not with glucose tolerance status whereas nerve myo-inositol levels positively correlated with signs of nerve regeneration (i.e. increased cluster density).

Diabet. Med. 17, 259-268 (2000)

Keywords human diabetes, IGT, peripheral nerve function, sorbitol, sural nerve

Abbreviations IGT, impaired glucose tolerance; MNFD, myelinated nerve fibre density 


\section{Introduction}

Nerve tissues obtained post mortem [1] or after amputation [2] from diabetic patients demonstrate elevated sorbitol levels. Elevated sorbitol levels have been associated with morphological changes in sural nerve and disturbed nerve function $[3,4]$ in diabetic patients. Pharmacological treatment with aldose reductase inhibitors designed to lower nerve sorbitol in diabetic patients has in some [4,5], but not in all [6], studies been connected with an improvement in nerve function. Published studies relating nerve sorbitol levels to nerve function in diabetic patients are sparse, however [3,4]. Moreover, these studies were performed in highly selected diabetic patients in tertiary referral centres or in clinical trials, and did not include individuals with impaired glucose tolerance (IGT). Low nerve levels of myo-inositol, another polyol, are associated with elevated nerve sorbitol levels in diabetic animals, and myo-inositol replacement therapy improves nerve function in some [7-9] but not all [10,11] animal studies. The pathophysiological importance of this inverse relationship between sorbitol and myo-inositol remains controversial [12-16]. In the current study, polyol levels and morphology of sural nerve were examined in relation to peripheral nerve function in men with diabetic, impaired, and normal glucose tolerance. The aims of this study were to relate nerve sorbitol levels, nerve myoinositol levels, and nerve morphology to quantitative peripheral nerve function and clinical neuropathy in the three groups with different glucose tolerance.

\section{Patients and methods}

\section{Patients}

From a prospective study started in 1975-1979, 69 men with Type 2 diabetes mellitus (duration of diabetes: median 14 (1) years), 51 men with persistent IGT, and 62 men with persistent normal glucose tolerance were assessed with regard to peripheral nerve function in 1989-1991 [17]. In 1992-1993, 10 subjects from each group (i.e. the number of subjects approved by the Ethics committee) were randomly invited (until 10 subjects in each group were recruited) to the current study. The investigation included a clinical neurological examination conducted by a neurologist (in all but one subject with IGT and one with normal glucose tolerance), a repeated neurophysiological evaluation of the leg, and a whole sural nerve biopsy performed soon after the clinical and neurophysiological examination. The Ethics committee of Lund University approved the project and, accordingly, after full written and verbal information about the biopsy procedure (provided separately both by the neurologist and the surgeon), all subjects gave their consent to the procedure.

\section{Neurophysiology}

Antidromic sensory neurography of the sural nerve was performed with one subcutaneous needle electrode inserted at the lateral malleolus and the reference electrode inserted $3 \mathrm{~cm}$ more distally. Stimuli were applied to the sural nerve at the calf about $15 \mathrm{~cm}$ more proximally. The surface temperature of the foot was kept at $30^{\circ} \mathrm{C}$ or above. Sensory thresholds for vibration, warm and cold sensations were estimated at the lateral side of the foot, within the skin area innervated by the sural nerve, using the Goldberg-Lindblom type vibrameter and the Termotest equipment (Somedic, Sweden) [18].

\section{Sural nerve sampling}

The surgical procedure for whole nerve sural biopsy was recently described [19]. Full-thickness 5-6 cm long sural nerve biopsies were immediately divided into five $1-\mathrm{cm}$ segments. The first, fourth and fifth (proximal to distal) segments were immediately frozen in liquid nitrogen and kept in $-70^{\circ} \mathrm{C}$ until shipped overnight frozen to the University of Michigan Nerve Biopsy Laboratory. The second and third segments were fixed in $0.1 \mathrm{M}$ cacodylate buffered ( $\mathrm{pH} 7.3$ ), 2.5\% glutaraldehyde and were then within 3 days shipped overnight to the Nerve Biopsy Laboratory where they were recorded with random identification numbers to conceal their identity from the analysis. The fixed $1-\mathrm{cm}$ segments were rinsed, further divided into 3 equal segments, post-fixed in $1 \%$ osmium ( $4 \%$ sucrose, $1.5 \%$ $\mathrm{K}_{3} \mathrm{Fe}(\mathrm{CN})_{6}$ in cacodylate buffer), dehydrated through ethanol $(50-100 \%)$ and placed in propylene oxide prior to embedding in Epon 812 such that the cut faces of the nerve incised at the time of biopsy were orientated toward the face of the block. After curing, a $1-\mu \mathrm{m}$ section from one of the faces transacted before fixation was cut on an ultramicrotome, and stained with toluidine blue for initial screening and quality scoring by a neuroanatomist according to predefined criteria (see below). If judged acceptable, adjacent $1-\mu \mathrm{m}$ sections cut from the same face were stained with $p$-phenylenediamine, which preferentially enhances the contrast of myelin, for quantitative computer-assisted light microscopic morphometric analysis. The identity, glucose tolerance status, and clinical status of the patients from whom the biopsies were collected were not revealed to the investigators at the University of Michigan until after all analytical data were transferred back to the clinical investigators in Sweden.

\section{Light microscopic morphometric analysis}

The largest fascicle meeting criteria for cross-sectional area $\left(\geqslant 100000 \mu \mathrm{m}^{2}\right)$, fixation, and mechanical distortion $(\leqslant 6 \%$ endoneurial area) was selected for light microscopic morphometric analysis [20]. A fascicle was defined as a group of nerve fibres surrounded by an outwardly convex, common perineurial membrane. Fascicle lobes were considered to be part of a single fascicle if a single convex, common perineurial membrane surrounded them. Connective tissue septa within fascicles were mapped and excluded from the calculation of fascicular area. If the largest fascicle so defined failed to meet criteria for fixation or mechanical distortion, the next largest fascicle in the same section was selected for measurement so long as its area exceeded $100000 \mu \mathrm{m}^{2}$. Adequacy of fixation was determined by preservation of microscopic structure, and by the absence of a staining gradient that would interfere with myelinated nerve 
fibre image acquisition in more than $6 \%$ of total fascicular area. Criteria for mechanical artefact included deviations from the normal ovoid perineurial profile that would alter endoneurial area by $>6 \%$, or localized distortion of myelinated nerve fibre profiles in regions corresponding to $>3 \%$ of total fascicular area. Absence of a suitable fascicle in the block initially sectioned resulted in sectioning of the block containing the opposite face of the nerve segment. If a suitable fascicle in that block could not be identified, the sample was deemed unreadable [20].

The selected fascicle was digitally imaged at $400 \times$ and analysed for total endoneurial area, the number of fibres, and the total and axon areas of each myelinated fibre by a semiautomated image analysis system [20]. The biopsies were digitized and analysed by readers and the identity of biopsies was concealed from them. Routinely, a different reader was used in order to calculate between-reader reproducibility and to ensure quality control $10 \%$ of the samples were re-read in the University of Michigan Nerve Biopsy Laboratory. The betweenreader coefficient of variation of myelinated nerve fibre density (MNFD) was routinely $<3 \%$. Fascicular area, myelinated fibre occupancy ( $\%$ fascicular area occupied by myelinated fibres), MNFD, mean and distribution of myelinated fibre and axonal diameters, the density of myelinated fibres within each $1-\mu \mathrm{m}$ increment in fibre diameter, axon/myelin ratio (ratio of axon diameter to fibre diameter) for each fibre, and the coefficient of variation of MNFD (CVMNFD), a measure of the degree of spatial homogeneity within the fascicle, were calculated from the digitized data.

Preliminary studies comparing MNFD in 20 large readable fascicles to that of the whole nerve specimen revealed a relative difference of $0.2 \pm 2.6 \%$. When the ratio of MNFD of each fascicle to the MNFD of the whole nerve specimen is plotted for all fascicles, there is a systematic deviation toward lower MNFD in fascicles $<50000 \mu \mathrm{m}^{2}$; therefore, $100000 \mu \mathrm{m}^{2}$ was used as a lower threshold for an acceptable fascicle [20].

\section{Electron microscopic morphometric analysis}

Following fascicle selection the block was trimmed and thin sections in the $80-90 \mathrm{~nm}$ range (silver-gold interference colour) were cut with a Diatom diamond knife (Diatome US, Ft Washington, PA) on a Reichert-Jung Ultracut E microtome (Leica Inc., Deerfield, IL). A single section was floated onto a $2 \times 1 \mathrm{~mm}$ Formvar coated copper slot grid (Electron Microscopy Services, Inc., Ft Washington, PA) stabilized with evaporated carbon film (Electron Microscopy Services). Five such grids were collected per sample and placed in a labelled, numbered grid storage box. To enhance contrast, each section was briefly washed in $50 \%$ methanol and immersed in a drop of $4 \%$ uranyl acetate in $50 \%$ methanol for $10 \mathrm{~min}$ (protected from light). The section was next washed briefly in $50 \%$ methanol and three separate distilled water rinses. It was then immersed in a drop of Reynolds lead citrate for $10 \mathrm{~min}$ (protected from carbon dioxide by sodium hydroxide pellets). The section was again washed in four separate distilled water rinses and allowed to air dry. The section was then further stabilized by sublimating spectrographically pure carbon (Ted Pella Inc., Redding, CA) onto the section using the rotating stage of a Denton Model DV-
502 vacuum evaporator (Denton, Moorestown, NJ). The stained grid was then placed in a Philips CM-100 electron microscope (North American Philips Co., Mahwah, NJ) with computer driven stage (CompuStage; North American Philips) and fitted with a Kodak Megaplus Camera, Model 1.6 (AMT) (Advanced Microscopy Techniques, Rowley, MS), for the digital montaging procedure.

Following image capture, montage formation and axon cueing, the virtual fascicle was examined by trained electron microscopy readers (Fig. 1). Specific definitions of the structures to be counted have been established to insure consistency from image to image and reader to reader. For the purpose of this
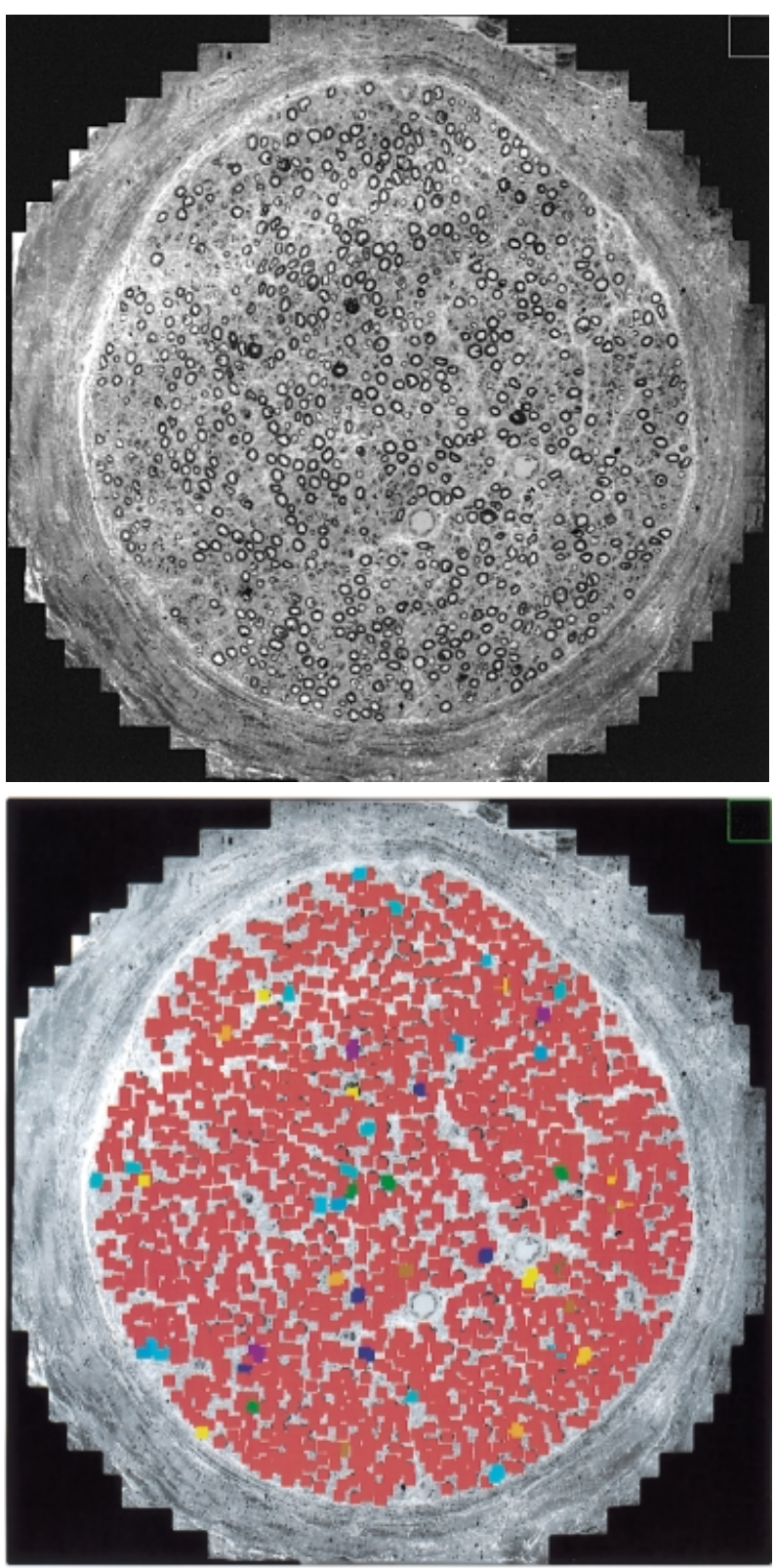

Figure 1 (a) A digitized and montaged image of an entire human sural nerve fascicle. (b) The same fascicle following automated cueing of the myelinated nerve fibres (red marks) and high-resolution human confirmation of regenerating clusters (all other colours). 
Table 1 Age, nerve function tests as well as biochemistry and morphology of sural nerve in subjects with diabetes, impaired glucose tolerance (IGT), and normal glucose tolerance

\begin{tabular}{|c|c|c|c|c|}
\hline & $\begin{array}{l}\text { Diabetes } \\
(n=10)\end{array}$ & $\begin{array}{l}\text { IGT } \\
(n=10)\end{array}$ & $\begin{array}{l}\text { Normal } \\
(n=10)\end{array}$ & $P$-values \\
\hline Age (years) & $62(2)^{\mathrm{a}}$ & $64(2)$ & $64(1)$ & 0.0195 \\
\hline \multicolumn{5}{|l|}{ Sural nerve function } \\
\hline Latency (ms) & $3.4(0.5)$ & $3.1(0.3)$ & $3.3(0.2)$ & 0.2251 \\
\hline Conduction velocity $(\mathrm{m} / \mathrm{s})$ & $41.0(6.0)^{\mathrm{b}}$ & $47.0(3.0)$ & $44.0(2.8)$ & 0.0454 \\
\hline Amplitudes $(\mu \mathrm{V})$ & $3.7(3.5)^{\mathrm{c}}$ & $11.3(10.6)$ & $10.0(11.6)$ & 0.0306 \\
\hline \multicolumn{5}{|l|}{ Sensory perception thresholds } \\
\hline Vibration $(\mu \mathrm{m})$ & $3.3(6)$ & $2.0(1.8)$ & $5.7(14.5)$ & 0.1809 \\
\hline Warm $\left({ }^{\circ} \mathrm{C}\right)$ & $8.5(9)$ & $6(3.5)$ & $6.75(4)$ & 0.5671 \\
\hline Cold $\left({ }^{\circ} \mathrm{C}\right)$ & $2.3(1.5)^{\mathrm{d}}$ & $4.8(2)$ & $3.3(2.5)$ & 0.0048 \\
\hline Biochemistry & $(n=10)$ & $(n=10)$ & $(n=10)$ & \\
\hline $\mathrm{HbA}_{1 \mathrm{c}}(\%)$ & $7.5(1.7)^{\mathrm{e}}$ & $5.0(1.0)$ & $4.6(0.8)$ & 0.0001 \\
\hline Glucose (pmol/mg protein) & $75260(38984)^{\mathrm{f}}$ & $52922(11286)$ & $45009(5037)$ & 0.0002 \\
\hline Sorbitol (pmol/mg protein) & $643(412)^{\mathrm{g}}$ & $286(83)$ & $296(250)$ & 0.0082 \\
\hline myo-inositol (pmol/mg protein) & $26877(7204)$ & $24686(7745)$ & $25297(4795)$ & 0.3580 \\
\hline Morphology & $(n=9)$ & $(n=9)$ & $(n=9)$ & \\
\hline \multicolumn{5}{|l|}{ Light microscopy } \\
\hline Myelinated nerve fibre density (MNFD) (fibres $/ \mathrm{mm}^{2}$ ) & $4460(1415)$ & $5090(1045)$ & $4750(1652)$ & 0.7015 \\
\hline Myelinated nerve fibre occupancy (\%) & $17(6)$ & $15(7)$ & $19(5)$ & 0.9791 \\
\hline Myelinated nerve fibre fascicle area $\left(\mathrm{mm}^{2}\right)$ & $227855(66535)$ & $196250(106480)$ & $245302(119099)$ & 0.9710 \\
\hline \multicolumn{5}{|l|}{ Electron microscopy } \\
\hline Myelinated nerve fibre density (MNFD) (fibres $/ \mathrm{mm}^{2}$ ) & $4446(793)$ & $4999(797)$ & $4708(4708)$ & 0.3222 \\
\hline Cluster density (definite clusters) & $25(26)$ & $10(29)$ & $10(10)$ & 0.2586 \\
\hline Density of axons in clusters & $50(50)$ & $23(58)$ & $20(27)$ & 0.2588 \\
\hline
\end{tabular}

Data as median (interquartile range).

$P$-values for Kruskal-Wallis variance analysis: ${ }^{\mathrm{a}} P=0.0121$ vs. IGT and $P=0.0297$ vs. normal; ${ }^{\mathrm{b}} P=0.0140$ vs. IGT; ${ }^{\mathrm{c}} P=0.0409$ vs. IGT and $P=0.0142$ vs. normal; ${ }^{\mathrm{d}} P=0.0011$ vs. IGT and $P=0.0842$ vs. normal; ${ }^{\mathrm{e}} P=0.0003$ vs. IGT and $P=0.0002$ vs. normal; ${ }^{\mathrm{f}} P=0.0009$ vs. IGT and $P=0.0003$ vs. normal; ${ }^{\mathrm{g}} P=0.0032$ vs. IGT and $P=0.0191$ vs. normal; ${ }^{\mathrm{h}} P=0.0019$ vs. IGT and $P=0.0019$ vs. normal in Mann-Whitney $U$-test.

regenerating cluster analysis, a regenerating cluster was defined as two or more myelinated axons surrounded by a common basal lamina (Fig. 2). The basal lamina must be $90 \%$ complete. Two or more myelinated axons surrounded by a common basal lamina that is less than $90 \%$ complete is considered a 'probable' cluster, and a single myelinated axon surrounded by an old basal lamina is considered a 'regenerating/remyelinating axon' but these were not included in the present analysis. This analysis thus constitutes a conservative estimate of regeneration, but increases the reproducibility of cluster counts among readers, giving a coefficient of variation of $10 \%$.

\section{Biochemical measurements}

Nerve glucose, sorbitol, myo-inositol, and fructose were measured by ion-selective gas-liquid chromatography/mass spectrometry and expressed as pmol/mg protein [21]. $\mathrm{HbA}_{1 \mathrm{c}}$ was determined by an automated high-performance liquid chromatography (HPLC) method (reference values 3.9-5.3\%) [22].

\section{Statistical analyses}

To avoid possible problems with skewed data, non-parametric statistical methods were consequently used. In agreement, the three groups were compared with Kruskal-Wallis variance analysis and, when significant, the Mann Whitney $U$-test was used for two group comparisons. For correlations, Spearman $r_{\mathrm{s}}$ were calculated. All tests were two-tailed and $P<0.05$ was considered significant. Data are presented as median (interquartile range).

\section{Results}

At time of sural biopsy, the group of diabetic patients were slightly younger compared with subjects with IGT and normal glucose tolerance (Table 1). At the neurological examination, clinical symptoms and/or signs of peripheral neuropathy were noted in five of the diabetic patients, in four of the IGT subjects, but in none of the subjects with normal glucose tolerance. Lack of ankle reflexes $(n=6)$, severe paraesthesia in the foot $(n=2)$, abnormal vibration sense (tuning fork) in combination with a defective perception of touch, paraesthesia and pains in the foot $(n=1)$ were demonstrated in subjects with clinical peripheral neuropathy.

\section{Neurophysiology}

Variance analysis revealed that sural nerve conduction velocities, sural nerve amplitudes, and cold perception thresholds significantly differed between the three groups 


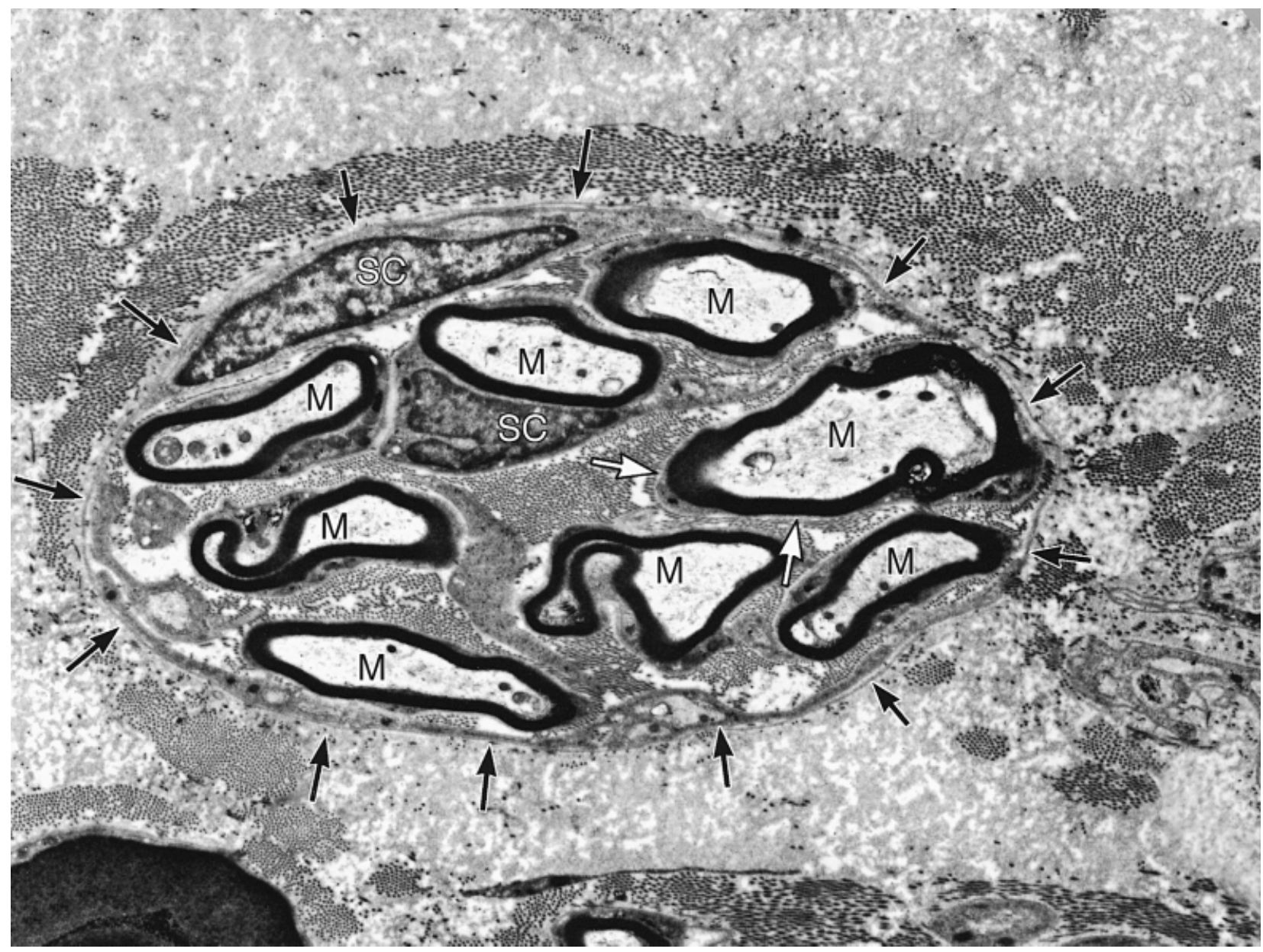

Figure 2 A regenerating cluster containing eight myelinated fibres (M) and two Schwann cell nuclei (SC). The original basal lamina (black arrows) completely encircles the regenerating myelinated fibres and their Schwann cells. A thin layer of Schwann cell cytoplasm surrounds each myelinated fibre (not labelled). Each regenerating myelinated fibre is also surrounded by a new basal lamina (white arrows) formed by the Schwann cells.

(Table 1). Sural nerve conduction velocities were significantly $(P=0.0140)$ lower in diabetic than in IGT subjects whereas sural nerve amplitudes were significantly lower in diabetic patients, both compared with IGT $(P=0.0409)$ and normally glucose tolerant $(P=0.0142)$ subjects. Perception thresholds for cold were significantly $(P=$ 0.0011) lower in diabetic than in IGT subjects; cold thresholds tended to be lower $(P=0.0842)$ in diabetic patients than in subjects with normal glucose tolerance as well.

\section{Biochemistry}

The levels of $\mathrm{HbA}_{1 \mathrm{c}}$ in the blood, and glucose, sorbitol, and fructose in the sural nerve were significantly higher in patients with diabetes compared with IGT and normal subjects, whereas there were no significant differences between IGT and normal subjects (Table 1). Nevertheless, there was a significant negative correlation $\left(r_{\mathrm{s}}=-0.69\right.$; $P=0.0376$ ) between sorbitol levels and sural amplitudes in IGT but not in diabetic $\left(r_{\mathrm{s}}=0.006\right)$ or normally glucose tolerant $\left(r_{\mathrm{s}}=0.29\right)$ subjects (Fig. 3). There was also a negative and significant correlation between sorbitol levels in sural nerve and cold perception thresholds $\left(r_{\mathrm{s}}=-0.61\right.$; $P=0.007)$ in diabetic and IGT subjects. As seen in Fig. 4, however, this correlation was noted in IGT $\left(r_{\mathrm{s}}=-0.49\right)$ and not in the diabetic $\left(r_{\mathrm{s}}=0.15\right)$ or the normally glucose tolerant $\left(r_{\mathrm{s}}=0.13\right)$ group. The myo-inositol levels did not differ significantly between the three groups.

\section{Nerve morphology}

There were no significant differences in nerve morphology between the three different groups (Table 1). There was a significant positive correlation (Fig. 5), however, between MNFD and sural amplitudes in subjects with diabetes and IGT $\left(r_{\mathrm{s}}=0.51 ; P=0.0374\right)$ but not in normally glucose tolerant subjects $\left(r_{\mathrm{s}}=-0.31 ; P=0.41\right)$. There were no significant correlations between sorbitol levels and nerve morphology. On the other hand, myo-inositol levels in sural nerve significantly correlated positively with cluster density (Fig. $6 ; r_{s}=0.56 ; P=0.0054$ ) and density of axons 


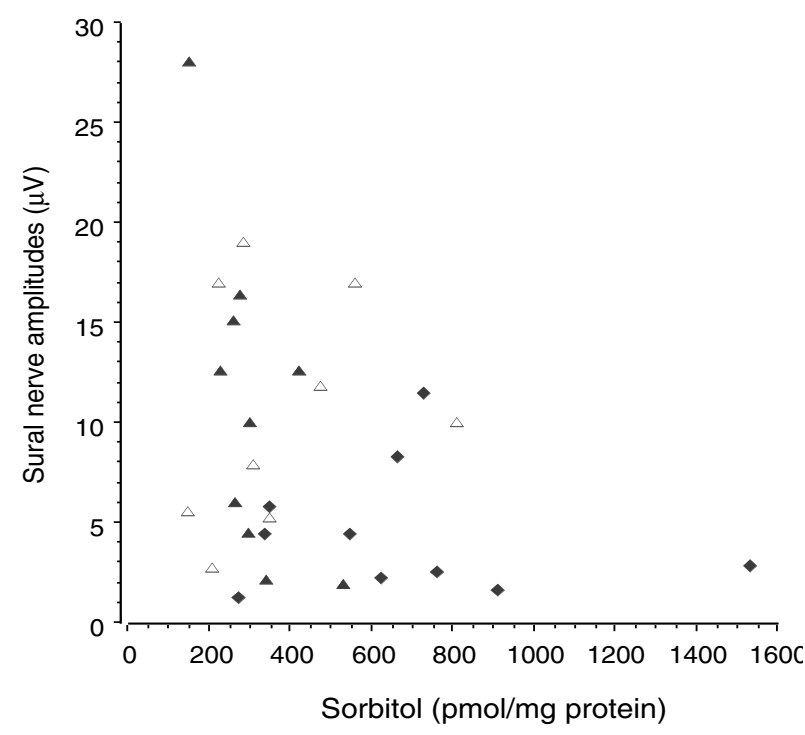

Figure 3 Correlation between sorbitol levels in sural nerve and sural nerve amplitudes among subjects with Type 2 diabetes (solid diamonds), impaired (solid triangles) glucose tolerance (IGT), and normal (open triangles) glucose tolerance. There was a significant negative correlation $\left(r_{\mathrm{s}}=-0.69 ; P=0.0376\right)$ between sorbitol levels and sural amplitudes in IGT but not in diabetic $\left(r_{\mathrm{s}}=0.006\right)$ or normally glucose tolerant $\left(r_{\mathrm{s}}=0.29\right)$ subjects

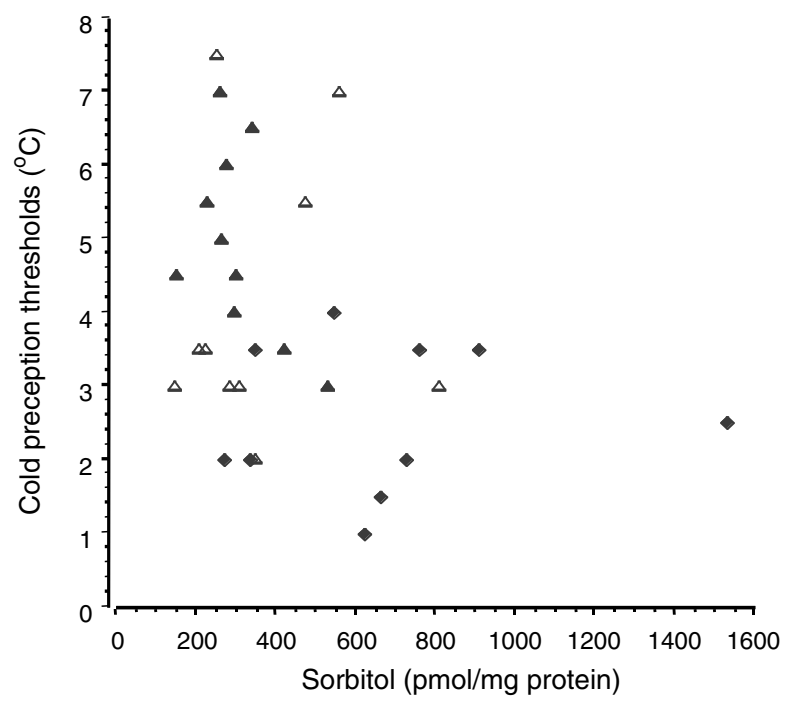

Figure 4 Correlation between sorbitol levels in sural nerve and cold perception thresholds among subjects with Type 2 diabetes (solid diamonds), impaired (solid triangles) glucose tolerance (IGT), and normal (open triangles) glucose tolerance. There was a significant negative correlation between sorbitol levels and cold perception thresholds in diabetic and IGT subjects $\left(r_{\mathrm{s}}=-0.61 ; P=0.007\right)$ confined to IGT subjects $\left(r_{\mathrm{s}}=-0.49 ; r_{\mathrm{s}}=-0.13\right.$ for diabetic subjects).

in clusters $\left(r_{s}=0.54 ; P=0.0073\right)$. Figure 6 shows that this correlation was found in subjects with IGT $\left(r_{\mathrm{s}}=0.51\right)$ and normal glucose tolerance $\left(r_{\mathrm{s}}=0.62\right)$. Hence, the positive correlation between myo-inositol levels and signs of nerve regeneration was a feature of the subjects with IGT and normal glucose tolerance.

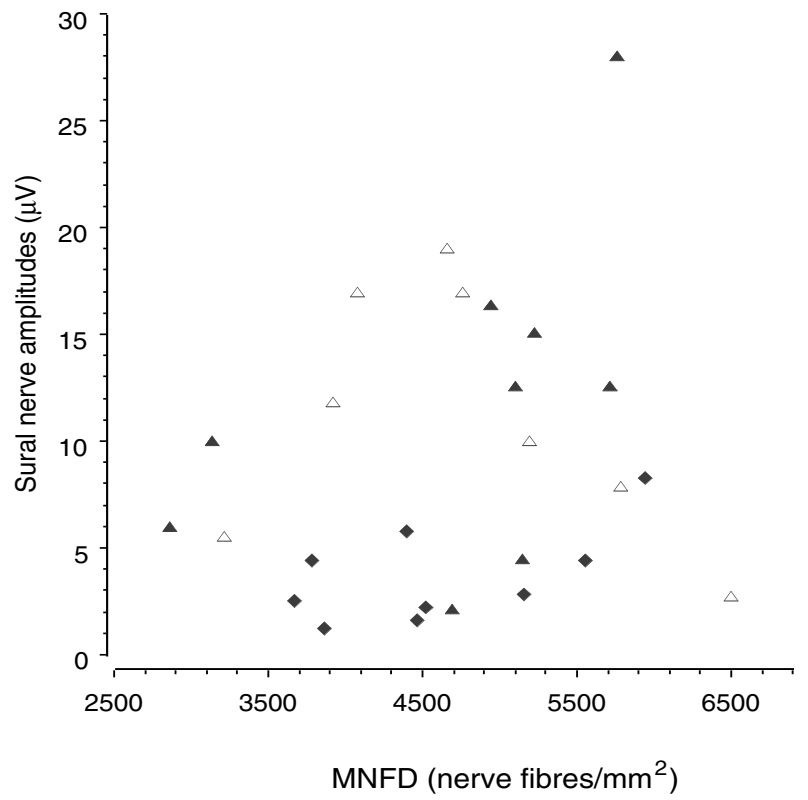

Figure 5 Correlation between myelinated nerve fibre density (MNFD) and sural nerve amplitudes among subjects with Type 2 diabetes (solid diamonds), impaired (solid triangles) glucose tolerance (IGT), and normal (open triangles) glucose tolerance. A positive correlation was found in subjects with diabetes or IGT $\left(r_{\mathrm{s}}=0.51 ; P=0.0374\right)$ but not in the subjects with normal glucose tolerance $\left(r_{\mathrm{s}}=-0.31\right.$; $P=0.4100)$.

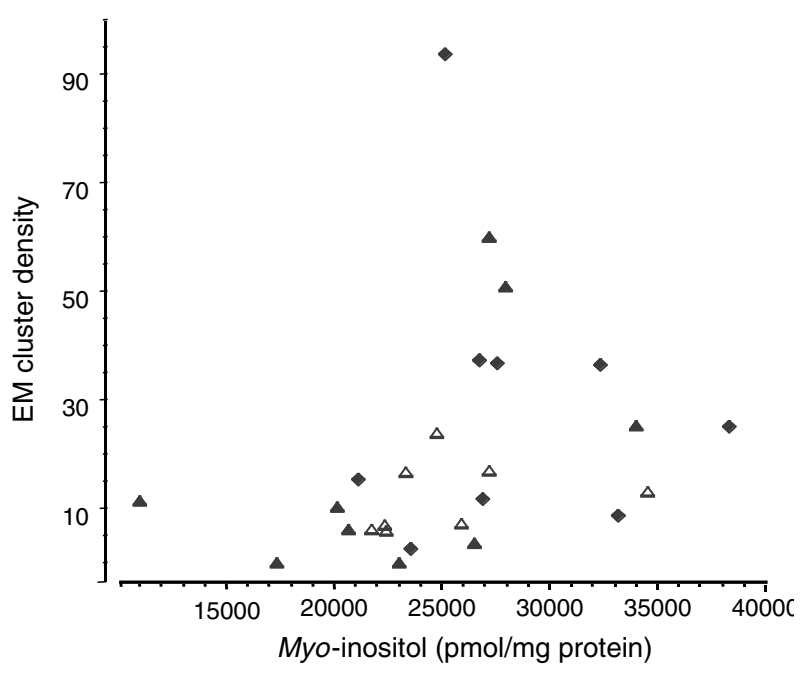

Figure 6 Correlation between myo-inositol levels and cluster density among subjects with Type 2 diabetes (solid diamonds), impaired (solid triangles) glucose tolerance (IGT), and normal (open triangles) glucose tolerance. There was a significant positive correlation $\left(r_{\mathrm{s}}=0.56\right.$; $P=0.0054)$ confined to subjects with IGT $\left(r_{\mathrm{s}}=0.51\right)$ and normal glucose tolerance $\left(r_{\mathrm{s}}=0.62\right)$.

\section{Clinical peripheral neuropathy}

Sural nerve amplitudes $(P=0.0246)$, MNFD (by light microscopy: $P=0.0021$; by electron microscopy: $P=0.0039)$, and fibre occupancy $(P=0.0039)$ were significantly lower in diabetic and IGT subjects with clinical peripheral neuropathy compared with those with- 
Table 2 Age, nerve function tests as well as biochemistry and morphology of sural nerve in diabetic and IGT subjects with and without clinical peripheral neuropathy

\begin{tabular}{|c|c|c|c|}
\hline & \multicolumn{3}{|c|}{ Peripheral neuropathy } \\
\hline & $\begin{array}{l}\text { With } \\
(n=9)\end{array}$ & $\begin{array}{l}\text { Without } \\
(n=10)\end{array}$ & $P$-values \\
\hline Age (years) & $64(2)$ & $63(2)$ & 0.5033 \\
\hline \multicolumn{4}{|l|}{ Sural nerve function } \\
\hline Latency (ms) & $3.3(0.5)$ & $3.1(0.3)$ & 0.2123 \\
\hline Conduction velocity $(\mathrm{m} / \mathrm{s})$ & $44.0(5.8)$ & $45.0(5)$ & 0.2120 \\
\hline Amplitudes $(\mu \mathrm{V})$ & $2.6(3.8)$ & $12.1(10.6)$ & 0.0246 \\
\hline \multicolumn{4}{|l|}{ Sensory perception thresholds } \\
\hline Vibration $(\mu \mathrm{m})$ & $3.5(3.4)$ & $2.0(1.8)$ & 0.4616 \\
\hline Warm $\left({ }^{\circ} \mathrm{C}\right)$ & $6(7)$ & $6.5(7.5)$ & 0.9673 \\
\hline Cold $\left({ }^{\circ} \mathrm{C}\right)$ & $3.5(1.3)$ & $3(3.5)$ & 0.6811 \\
\hline \multicolumn{4}{|l|}{ Biochemistry } \\
\hline $\mathrm{HbA}_{1 \mathrm{c}}(\%)$ & $5.8(2.6)$ & $6.0(2.6)$ & 0.9348 \\
\hline Sorbitol (pmol/mg protein) & $527(326)$ & $306(406)$ & 0.2530 \\
\hline Fructose (pmol/mg protein) & $2558(1889)$ & $1593(3761)$ & 0.3691 \\
\hline myo-inositol (pmol/mg protein) & $25049(4728)$ & $27410(6677)$ & 0.1651 \\
\hline \multicolumn{4}{|l|}{ Morphology } \\
\hline \multicolumn{4}{|l|}{ Light microscopy } \\
\hline Myelinated nerve fibre density (MNFD) (fibres $/ \mathrm{mm}^{2}$ ) & $4076(1091)$ & $5219(668)$ & 0.0021 \\
\hline Myelinated nerve fibre occupancy (\%) & $14(3)$ & $21(6)$ & 0.0039 \\
\hline Myelinated nerve fibre fascicle area $\left(\mathrm{mm}^{2}\right)$ & $209250(117459)$ & $238635(83759)$ & 0.8474 \\
\hline \multicolumn{4}{|l|}{ Electron-microscopy } \\
\hline Myelinated nerve fibre density (MNFD) (fibres $/ \mathrm{mm}^{2}$ ) & $4387(766)$ & $5121(839)$ & 0.0039 \\
\hline Cluster density (definite clusters) & $26(44)$ & $12(18)$ & 0.7003 \\
\hline Density of axons in clusters & $53(93)$ & $30(35)$ & 0.7003 \\
\hline
\end{tabular}

Data as median (interquartile range). $P$-values for Mann-Whitney $U$-test

out (Table 2). Noteworthy, among subjects with peripheral neuropathy, the three with paraesthesia had significantly higher cluster density than the five without such symptoms (60 (42) vs. 6 (19) clustered nerve fibres $/ \mathrm{mm}^{2}$; $P=0.0253)$. Amongst diabetic patients, myo-inositol levels were significantly $(P=0.0283)$ lower in those with (25049 (3985) $\mathrm{pmol} / \mathrm{mg}$ protein) than in those without (32253 (7503) pmol/mg protein) clinical peripheral neuropathy.

\section{Side-effects of biopsy}

As already reported [19], 20-44 months after the biopsy one forth of patients reported serious complaints. At the most recent follow up conducted 5-7 years after the biopsy, 14 of $20(70 \%)$ assessed subjects still reported complaints. The complaints were considered as minor (not major pain but discomfort, 'numbness' and loss of sensation); however, none of the subjects would have accepted a new biopsy if it had been offered.

\section{Discussion}

This study has shown that impaired sural nerve function is associated with elevated sorbitol levels in sural nerve in diabetic patients. Sorbitol levels were, however, negatively associated with sural amplitudes in IGT subjects. Accumulation of sorbitol in nerve tissue may therefore have a role in the early development of neuropathy. Sural nerve morphology was similar in the three groups with different degrees of glucose tolerance. Hence, biochemical deviations and disturbed nerve function in diabetes may precede detectable degeneration and loss of myelinated nerve fibres. In keeping with this, clinical neuropathy was associated with alterations in myelinated nerve fibre morphology: MNFD was clearly less in subjects with clinical neuropathy than in those without. Low nerve myoinositol levels have been considered as a putative mechanism behind diabetic neuropathy [23,24]. In this study, signs of nerve regeneration (cluster density) were high in subjects with high myo-inositol levels. High myo-inositol levels may therefore promote nerve regeneration thereby perhaps delaying or preventing the early development of clinical diabetic neuropathy.

In the current study, sural nerve functions were disturbed in the diabetic but not in the IGT group. This confirms prior results in the original cohort [17] and illustrates that representative subgroups participated in our biopsy study. In addition, ideal controls were used, i.e. the biopsies were obtained from controls not only normal 
with regard to glucose tolerance but also carefully assessed to exclude peripheral neuropathy, which is recommended [25].

A conspicuous finding was the observation that sensory perception thresholds for cold were decreased in the diabetic group i.e. diabetic patients showed increased cold perception. An increased intolerance to cold was also noted in the diabetic patients compared with controls at followup [19]. From the clinical point of view, this finding of an increased cold perception in diabetic patients is of relevance. It is well-known that diabetic patients often complain of cold feet without signs of vascular dysfunction [26]; diminished thresholds for cold could be the rational behind allodynia (increased perception), a well-known feature of diabetic neuropathy. The correlation between high sorbitol levels and low cold thresholds fits with the concept that low thresholds for cold indicate disturbed nerve function. An increased frequency of cold intolerance in non-diabetic subjects with nerve injury as a result of vibration [27], hand trauma [28], and hand operations [29] is another argument for this concept.

The association between high sorbitol levels and disturbed sural nerve functions in diabetic patients confirms a previous report [3]. Polyol levels have previously not been assessed in subjects with IGT. This study shows that polyol levels do not differ between IGT and subjects with normal glucose tolerance. Nevertheless, there was an association between sorbitol levels and sural nerve amplitudes in IGT subjects. The present study therefore infers that sorbitol may have a fundamental role for human nerve function i.e. slight alterations in sorbitol levels may impair nerve function. This is in agreement with previous observations that disturbed peripheral nerve function may be detected at the diagnosis of diabetes [30] quickly reversible when diabetic metabolic deterioration is reversed by insulin treatment [31]. Concordant to experimental diabetes in animals [32], the present study shows that there is impairment in peripheral nerve function of metabolic origin in humans. The lack of correlation between sorbitol levels and sural nerve amplitudes in the diabetic patients indicates that when the sorbitol concentration in the nerve has reached a certain high level, the putative mechanism that links sorbitol levels to disturbed nerve function is saturated.

The clinical consequences of this correlation between peripheral nerve dysfunction and disturbed carbohydrate metabolism have to be considered. Neurophysiological signs of disturbed nerve function were a feature of diabetes and not of IGT; whereas, on the other hand, clinical peripheral neuropathy was as frequent in IGT as in diabetes. Subjects with clinical peripheral neuropathy (whether with diabetes or IGT) showed signs of nerve degeneration (low fibre density and occupancy) and this was associated with low sural amplitudes. Conversely, there were no differences in nerve morphology between the groups with diabetes, IGT, and normal glucose tolerance. Accordingly, nerve degeneration was associated with clinical neuropathy rather than with diabetes in general. This suggests that features other than glucose tolerance status may determine the sensitivity of the peripheral nervous system to subtle alterations in carbohydrate metabolism. Nerve myo-inositol levels emerge as one such possible factor in this study.

The correlation between nerve degeneration and clinical neuropathy confirms previous findings of a correlation between clinical neuropathy and nerve morphology $[13,33]$. In this context, it is of interest that the current study found a positive correlation between paraesthesia and nerve regeneration (cluster density). This finding of an association between morphological nerve changes and clinical neuropathy in subjects with IGT is a new and important observation. Glucose levels considered to be diagnostic for diabetes are based on associations between glucose levels of certain magnitude and the development of retinopathy and nephropathy [34]. The present study indicates that glucose and $\mathrm{HbA}_{1 \mathrm{c}}$ values in the IGT range may be dangerous for nerve tissue, at least in susceptible individuals. Indeed, in our original study of the complete cohort, it was discovered that $29 \%$ of the IGT patients had signs of autonomic neuropathy [17]. In fact, a lack of Achilles' tendon reflexes as a sign of peripheral neuropathy has previously been reported to be more frequent in IGT than in subjects with normal glucose tolerance [35]. Hence, nerve tissue seems to be especially vulnerable to hyperglycaemia and its consequences and this could explain why neuropathy might be the most frequent complication to diabetes [36].

If nerve degeneration is a feature of clinical neuropathy, how could this be related to the polyol findings? Myoinositiol depletion, secondary or not to sorbitol accumulation, has been thought to be a contributing factor to diabetic neuropathy [23]. In the current study, high myoinositol levels were associated with nerve regeneration (high cluster density) and myo-inositol levels were low in diabetic patients with clinical neuropathy. It is therefore tempting to speculate that myo-inositol promotes nerve regeneration, perhaps by modulating some aspects of phosphoinositide signal transductions [24] and/or vascular sympathetic tone [37]; elevated myo-inositol levels may be considered as a compensatory mechanism against MNFD loss. The present data suggest that perhaps $30 \%$ of the variation in cluster density or axon diameter may be attributed to differences in myo-inositol.

The present study revealed a new and previously not reported finding, i.e. clinical peripheral neuropathy associated with morphological signs of nerve degeneration and disturbed nerve regeneration may occur in subjects with IGT and not only in diabetic patients. This observation may change the current concept of the pathogenesis to diabetic neuropathy. This information was, however, 
gained by biopsies that had obvious long-term side-effects. Sural nerve biopsy, including biopsy of normal individuals, is an accepted research procedure in the field of peripheral neuropathy [3,38-41]. Indeed, the use of normal controls is specifically recommended in the authoritative textbook on nerve biopsy [42]. Nevertheless, the long-term complaints indicate that the reason for sural nerve biopsy must always be carefully considered before a biopsy is undertaken [43].

In conclusion, this study supports the assumption that disturbed glucose metabolism by alterations in polyols affects the human peripheral nervous system in two different ways: increments in sorbitol levels impair peripheral nerve function and decrements in myo-inositol levels impair nerve regeneration.

\section{Acknowledgements}

The authors thank Christina Rosborn for excellent technical assistance with regard to the collection of the biopsy material. The Child Diabetes Fund, Crafoord Foundation, Heart Lung Foundation, Lundström Foundation, Malmö Diabetes Association, Novo-Nordic Foundation, Research Funds Malmö University Hospital, Albert Påhlson Foundation, Swedish Diabetes Association, Swedish Medical Research Council (7507, 084), University Funds Lund University, and Hoffman La Roche Pharmaceutical supported this study.

\section{References}

1 Mayhaw JA, Gillon KRW, Hawthorne JN. Free and lipid inositiol, sorbitol, and sugars in sciatic nerve obtained post-mortem from diabetic patients and control subjects. Diabetologia 1983; 24: 1315.

2 Hale PJ, Nattrass M, Silverman SH, Sennit C, Perkins CM, Udén A et al. Peripheral nerve concentrations of glucose, fructose, sorbitol and myo-inositol in diabetic and non-diabetic patients. Diabetologia 1987; 30: 464-467.

3 Dyck PJ, Zimmerman BR, Vilen TH, Minnerath SR, Karnes JL, Yao JK et al. Nerve glucose, fructose, sorbitol, myo-inositol, and fiber degeneration and regeneration in diabetic neuropathy. N Eng J Med 1988; 319: 542-548.

4 Sima AAF, Bril V, Nathaniel V, McEwan AJ, Brown MB, Lattimer SA et al. Regeneration and repair of myelinated fibers in sural-nerve biopsy specimen from patients with diabetic neuropathy treated with sorbinil. N Eng J Med 1988; 319: 548-555.

5 Sima AAF, Prashar A, Nathaniel V, Bril V, Werb MR, Greene DA. Overt diabetic neuropathy: repair of axo-glial dysjunction and axonal atrophy by aldose reductase inhibition and its correlation to improvement in nerve conduction velocity. Diabetic Med 1993; 10: 115-121.

6 Pfeifer MA, Schumer MP, Gelber DA. Aldose reductase inhibitors: the end of an era or the need for different trial designs. Diabetes 1997; 46: S82-S89.

7 Greene DA, Chakrabarti S, Lattimer SA, Sima AA. Role of sorbitol accumulation and myo-inositol depletion in paranodal swelling of large myelinated nerve fibers in the insulin-deficient spontaneously diabetic bio-breeding rat. Reversal by insulin replacement, an aldose reductase inhibitor, and myo-inositol. J Clin Invest 1987; 79: 1479_ 1485.
8 Tomlinson DR, Mayer JH. Reversal of deficits in axonal transport and nerve conduction velocity by treatment of streptozotocindiabetic rats with myo-inositol. Exp Neurol 1985; 89: 420-427.

9 Stevens MJ, Dananberg J, Feldman EL, Lattimer SA, Kamijo M, Thomas TP et al. The linked roles of nitric oxide, aldose reductase and, $\left(\mathrm{Na}^{+}, \mathrm{K}^{+}\right)$-ATPase in the slowing of nerve conduction in the streptozotocin diabetic rat. J Clin Invest 1994; 94: 853-859.

10 Cameron NE, Cotter MA, Dines KC, Maxfield EK, Carey F, Mirrlees DJ. Aldose reductase inhibiton, nerve perfusion, oxygenation and function in streptozotocin-diabetic rats: dose-response considerations and independence from a myo-inositol mechanism. Diabetologia 1994; 37: 651-663.

11 Jeffreys JGR, Palmano KP, Sharma AK, Thomas PK. Influence of dietary myoinositol on nerve conduction and inositol phospholipids in normal and diabetic rats. J Neurol Neurosurg Psychiatry 1978; 41: 333-339.

12 Tomlinson DR. Polyols and myo-inositol in diabetic neuropathy - of mice and men. Mayo Clin Proc 1989; 64: 1030-1033.

13 Dyck PJ, Sherman WR, Hallcher LM, Service FJ, O'Brian PC, Grina LA et al. Human diabetic endoneurinal sorbitol, fructose and myoinositol related to sural nerve morphometry. Ann Neurol 1980; 8: 590-596.

14 Dyck PJ. Detection, characterization, and staging of polyneuropathy: assessed in diabetics. Muscle Nerve 1988; 11: 21-32.

15 Stevens MJ, Lattimer SA, Feldman ED, Helton DS, Millington AAF, Sima AAF et al. Acetyl-L-carnitine deficiency as a cause of altered nerve myo-inositol content, $\mathrm{Na}, \mathrm{K}$-ATPase activity, motor conduction velocity in the streptozotocin-diabetic rat. Metabolism 1996; 45: 865-872.

16 Low PA, Yao JK, Kishi Y, Tritschler HJ, Schmelzer JD, Zollman PJ et al. Peripheral nerve energy metabolism in experimental diabetic neuropathy. Neuroscience Res Com 1997; 21: 49-56.

17 Eriksson KF, Nilsson H, Lindgärde F, Österlin S, Dahlin L-B, Lilja B et al. Diabetes mellitus but not impaired glucose tolerance is associated with dysfunction in peripheral nerves. Diabetic Med 1994; 11: 279-285.

18 Sundkvist G, Lilja B, Nilsson H, Nilsson JÅ, Rosén I. Peripheral nerve dysfunction is reflected by loss of ankle reflexes but not by autonomic neuropathy in diabetic patients. Muscle Nerve 1997; 20: 740-743.

19 Dahlin LB, Eriksson K-F, Sundkvist G. Persistent postoperative complaints after whole sural nerve biopsies in diabetic and nondiabetic subjects. Diabetic Med 1997; 14: 353-356.

20 Greene DA, Brown MB. Validation of sural nerve fiber density and percent normal teased fibers as morphological endpoints in clinical trials of diabetic neuropathy. In Hotta N, Greene DA, Ward JD, Sima AAF, Boulton AJM. eds. Diabetic Neuropathy: New Concepts and Insights. Amsterdam: Exerpta Medica, Elsevier, 1995: 379-385.

21 Sima AAF, Greene DA, Brown MB, Hohman TC, Hicks D, Graepel GJ et al. Effect of hyperglycemia and the aldose reductase inhibitor tolrestat on sural nerve biochemistry and morphometry in advanced diabetic peripheral polyneuropathy. J Diab Comp 1993; 7: 157-169.

22 Jeppsson J-O, Jerntorp P, Sundkvist G, Englund H, Nylund V. Measurement of hemoglobin A1c by a new liquid-chromatographic assay: methodology, clinical utility, and relation to glucose tolerance evaluated. Clin Chem 1986; 32: 1867-1872.

23 Clements RS, Reynertson R. Myo-inositol metabolism in diabetes mellitus. Effect of insulin treatment. Diabetes 1977; 26: 215-221.

24 Stevens MJ, Feldman EI, Greene DA. The aetiology of diabetic neuropathy: the combined roles of metabolic and vascular defects. Diabetic Med 1995; 12: 566-579.

25 Giannini C. Ultrastructural morphometric analysis of human sural nerve biopsies. Diabetic Med 1996; 13: 675-676.

26 Watkins PJ, Edmonds ME. Clinical features of diabetic neuropathy. 
In Pickup JC, Williams G. eds. Textbook of Diabetes Oxford: Blackwell Science, 1997.

27 Stromberg T, Dahlin LB, Lundborg G. Hand problems in 100 vibration-exposed symptomatic male workers. Hand Surg (Br) 1996; 21B: 315-319.

28 Birch R, Raji A. Repair of median and ulnar nerves. Primary suture is best. J Bone Joint Surg 1991; 73B: 154-157.

29 Engkvist O, Wahren LK, Wallin G, Torebjork EBN. Effects of regional guanethidine block in posttraumatic cold intolerance in hand amputees. J Hand Surg 1985; 10B: 145-150.

30 Gregersen G. Variations in motor conduction velocity produced by acute changes of the metabolic state in diabetic patients. Diabetologia 1968; 4: 273-277.

31 Gregersen G. Diabetic neuropathy. influence of age, sex, metabolic control, and duration of diabetes on motor conduction velocity. Neurology 1967; 17: 972-980.

32 Tomlinson DR. Aldose reductase inhibitors and the complications of diabetes mellitus. Diabetic Med 1993; 10: 214-230.

33 Llewelyn JG, Gilbey SG, Thomas PK, King RHM, Muddle JR, Watkins PJ. Sural nerve morphometry in diabetic autonomic and painful sensory neuropathy. A clinicopathological study. Brain 1991; 114: 867-892.

34 The Expert Committee on the Diagnosis and Classification of Diabetes Mellitus. Report of the expert committee on the diagnosis and classification of diabetes mellitus. Diabetes Care 1997; 20: 1183-1197.

35 De Neeling JND, Beks PJ, Bertelsmann FW, Heine RJ, Bouter LM.
Peripheral somatic nerve function in relation to glucose tolerance in an elderly Caucasian population: the Hoorn Study. Diabetic Med 1996; 13: 960-966.

36 Drejgaard A. Pathophysiology and treatment of diabetic neuropathy. Diabetic Med 1998; 15: 97-112.

37 Shindo H, Thomas TP, Larkin DD, Karihaloo AK, Inada H, Onaya T et al. Modulation of basal nitric oxide-dependent cyclic-GMP production by ambient glucose, myo-inositol, and protein kinase $\mathrm{C}$ in SH-SY5Y human neuroblastoma cells. J Clin Invest 1996; 97: 736-745.

38 Dyck PJ, Karnes JL, Daube J, O’Brien P, Service FJ. Clinical and neuropathological criteria for the diagnosis and staging of diabetic polyneuropathy. Brain 1985; 108: 861-880.

39 Dyck PJ, Lais A, Karnes JL, O'Brien P, Rizza R. Fibre loss in primary and multifocal in sural nerves in diabetic polyneuropathy. Ann Neurol 1986; 19: 425-439.

40 Proceedings of a Consensus Development Conference on Standardized Measure in Diabetic Neuropathy. Morphological and biochemical measures. Neurology 1992; 42: 1825-1826.

41 Russell JW, Karnes JL, Dyck PJ. Sural nerve myelinated fiber density differences associated with meaningful changes in clinical and electrophysiologic measurement. J Neurol Sci 1996; 135: 114-117.

42 Midroni G, Bilbao JM. Chapter 3. Quantitative techniques. In Biopsy Diagnosis of Peripheral Neuropathy, Boston: ButterworthHeinemann, 1995: 37.

43 Thomas PK. Nerve biopsy. Diabetic Med 1997; 14: 345-346. 